\title{
Impaired response of pancreatic polypeptide to hypoglycaemia: an early sign of autonomic neuropathy in diabetics
}

\author{
T KRARUP, T W SCHWARTZ, J HILSTED, S MADSBAD, O VERLAEGE, L SESTOFT
}

British Medical fournal, 1979, 2, 1544-1546

\section{Summary and conclusions}

The pancreatic polypeptide (PP) response to insulininduced hypoglycaemia was studied in 18 juvenile diabetics and was calculated as the difference between the prestimulatory PP concentration and the maximal concentration measured. The response was severely impaired in patients with autonomic neuropathy (mean \pm SE of mean $22 \pm 12 \mathrm{pmol} / \mathrm{l}$ ) as compared with patients without neuropathy $(252 \pm 51 \mathrm{pmol} / 1)$. Patients whose diabetes was of only a few years' duration showed a normal PP response to hypoglycaemia, and the response diminished significantly with increasing duration of diabetes. The decreased PP response to hypoglycaemia was significantly correlated with an increased threshold of the sense of vibration, $\left(r_{s}=-0 \cdot 86\right)$.

These results suggest that impaired secretion of PP may serve as an early sign of autonomic neuropathy in diabetes.

\section{Introduction}

Autonomic neuropathy in diabetics affects the vagal nerves. ${ }^{1}$ Thus findings in patients with gastrointestinal neuropathy are similar to those in patients who have undergone surgical vagotomy. ${ }^{12}$ The term "autovagotomy" has even been used. ${ }^{3}$ An example of vagal dysfunction in diabetic autonomic neuropathy is when secretion of gastric acid cannot be stimulated via the vagus by hypoglycaemia but can still be activated by the humoral stimulus pentagastrin. ${ }^{4}$

The secretion of the hormone pancreatic polypeptide (PP) is regulated by vagal, cholinergic stimulation ${ }^{5}$; and both the spontaneous $^{6} 7$ and the food-mediated ${ }^{8} 9$ secretion of PP depend on vagal, cholinergic mechanisms. A reliable test of the vagal-nerve supply of PP cells is insulin-induced hypoglycaemia. Thus the PP response to hypoglycaemia is completely eliminated by vagotomy. ${ }^{510}$ We have used insulin-induced hypoglycaemia to assess the damage to the vagal nerves caused by different gastric operations. ${ }^{11}$

Hvidøre Hospital, Klampenborg, Denmark

T KRARUP, MD, registrar

J HILSTED, MD, postgraduate research fellow (Institute of Medical Physiology B, University of Copenhagen)

$S$ MADSBAD, $M D$, postgraduate research fellow

L SESTOFT, MD, chief physician

Institute of Medical Biochemistry, University of Aarhus, Dk-8000, Aarhus, Denmark

T W SCHWARTZ, MD, postdoctoral research fellow (now post-doctoral fellow and research associate, department of biochemistry, University of Chicago)

O VERLAEGE, PHD, visiting research fellow (State University of Utrecht, The Netherlands)
In the present investigation we studied the PP response to insulin-induced hypoglycaemia in juvenile diabetics with and without autonomic neuropathy.

\section{Patients and methods}

We studied 22 patients with insulin-dependent diabetes who were prone to ketosis. Thirteen had no sign of autonomic neuropathy; their mean age was 28 (range 21-33 years), mean duration of diabetes $5 \cdot 5$ (range $0.5-15)$ years, and mean ( \pm SE of mean) beat-to-beat variation $24 \pm 2$ beats/min. Five patients had autonomic neuropathy; their mean age was 30 (range 26-39) years and mean duration of diabetes 15 (range 5-31) years. There was no significant difference between the duration of diabetes in the two groups $(P>0 \cdot 10)$. Two further patients in each group were excluded because they had antibodies against PP. The criteria for autonomic neuropathy were decreased beat-to-beat variation in heart rate during deep breathing ${ }^{12}$ (four patients) and orthostatic hypotension (two patients); the table shows the clinical findings. In all but one patient the sense of vibration was evaluated by

Clinical findings in patients with autonomic neuropathy

\begin{tabular}{lccccc}
\hline & Case 1 & Case 2 & Case 3 & Case 4 & Case 5 \\
\hline Beat-to-beat variation (beats/min) & 7 & 8 & 2 & 12 & 20 \\
$\begin{array}{l}\text { Orthostatic hypotension } \\
\text { Reduced sweat secretion }\end{array}$ & \pm & \pm & \pm & \pm & \pm \\
Gustatory sweating & \pm & \pm & \pm & & \pm \\
$\begin{array}{l}\text { Impotence } \\
\text { Sensory threshold (V) }\end{array}$ & 20 & 20 & 48 & 40 & 13 \\
Retinopathy: & & & \pm & \pm & \pm \\
$\quad$ Proliferative & \pm & \pm & & & \pm \\
\hline Background & & & & &
\end{tabular}

biothesiometry. ${ }^{13}$ In all patients serum creatinine concentrations were within the normal range; and no patient received any medication besides insulin. All patients gave informed, signed consent to the investigation.

Hypoglycaemia-During the 48 hours preceding the study the patients were treated with only soluble insulin given subcutaneously (Actrapid, Novo, Denmark) to eliminate depots of intermediateacting insulins. During the last 10 hours before the study began soluble insulin was given as an intravenous infusion to attain steady blood glucose concentrations of $6-8 \mathrm{mmol} / 1(108-144 \mathrm{mg} / 100 \mathrm{ml})$. Hypoglycaemia was achieved by infusing $0.15 \mathrm{U}$ soluble insulin $/ \mathrm{kg} / \mathrm{h}$ for 30-110 minutes. The infusion was continued until the patients showed symptoms of hypoglycaemia; during the infusion blood glucose concentrations were monitored. (Eyetone reflectance meter, Ames). The mean $(+\mathrm{SE}$ of mean) nadir in blood glucose concentrations was $1.9+0.1 \mathrm{mmol} / 1(34.2 \pm 1.8 \mathrm{mg} / 100 \mathrm{ml})$ in patients with neuropathy and $2 \cdot 1 \pm 0 \cdot 2 \mathrm{mmol} / 1(37.8 \pm 3.6 \mathrm{mg} / 100 \mathrm{ml})$ in patients without neuropathy, the concentrations being determined by a glucose oxydase method. ${ }^{14}$

$P P$ radioimmunoassay was performed with antiserum $146-5$ and iodinated $\mathrm{bPP}_{1-36}$ as described..$^{5}$ Blood samples for measurements of PP were taken before the infusion of insulin (average of two samples taken as basal value) and up to 120 minutes after stopping the infusion.

Calculations-The PP response to hypoglycaemia was calculated as the difference between the prestimulatory concentration and the maximal concentration measured. The Mann-Whitney $U$ test and Spearman's coefficient of correlation were used for statistical evaluations; $\mathrm{P}<0.05$ was considered to be significant. All results are presented as mean $+\mathrm{SE}$ of mean. 


\section{Results}

Before the insulin infusion no difference was found in plasma concentrations of PP between patients with and without neuropathy $(20 \pm 5$ and $22 \pm 4 \mathrm{pmol} / 1$ respectively). The PP response to hypoglycaemia among patients with neuropathy $(22 \pm 12 \mathrm{pmol} / \mathrm{l})$ was significantly smaller than that among patients without neuropathy $(252 \pm 51 \mathrm{pmol} ; \mathrm{P}<0.01)$. The patient with orthostatic hypotension but with a normal vagal innervation of the heart as evaluated by beatto-beat variation (case 5) had an intermediate PP response (106 pmol/1). When the group of patients without neuropathy was divided according to the duration of diabetes those patients with a short duration of diabetes $(<5.5$ years; $n=7)$ showed a normal ${ }^{15} \mathrm{PP}$ response to hypoglycaemia $(342 \pm 68 \mathrm{pmol} / \mathrm{l})$; whereas patients with a long duration of diabetes $(>8.5$ years; $n=6)$ showed an appreciably smaller response $(147 \pm 56 \mathrm{pmol} / \mathrm{l})$ (fig 1). Thus patients with a long

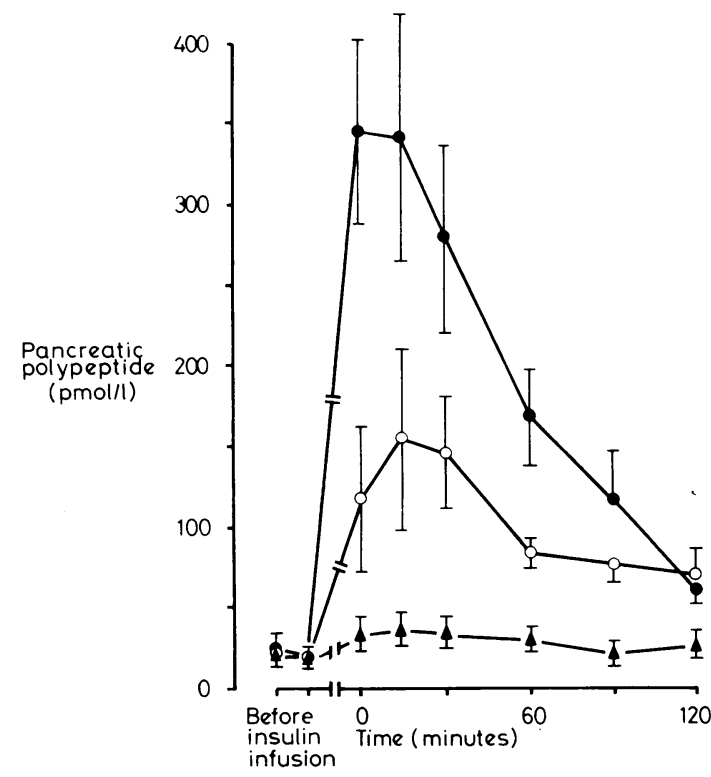

FIG 1-Response of pancreatic polypeptide to insulininduced hypoglycaemia in patients without measurable neuropathy with either short duration of diabetes $(0 \cdot 5-5 \cdot 5$ years $; n=7)(-0)$, or long duration of diabetes $(8 \cdot 5-15$ years; $n=6)(0-0)$; and in diabetics with autonomic neuropathy $(n=4$; duration of diabetes $5-15$ years $)$ $(\triangle \longrightarrow \triangle)$. Time zero indicates time when insulin infusion stopped.

duration of diabetes, who had no measurable signs of autonomic neuropathy, had a reduced PP response to insulin-induced hypoglycaemia, but this response was not as small as that in patients with a similar duration of illness but with autonomic neuropathy.

There was a significant inverse correlation between the PP response to hypoglycaemia and the threshold of the sense of vibration both when all patients were considered as one group $\left(r^{s}=-0.86, P<0.001\right.$, $\mathrm{n}=17$ ) and when only patients without neuropathy were tested, $\left(r_{s}=-0.82, P<0.01, n=12\right.$-fig 2).

\section{Discussion}

These results show that juvenile diabetics with overt neuropathy have a greatly impaired PP response to hypoglycaemia, which accords with findings in maturity-onset diabetics with autonomic neuropathy ${ }^{16}$ (N S Levitt and A I Vinik, personal communication). Patients with a long duration of diabetes but without measurable signs of autonomic neuropathy, however, also have a reduced PP response compared with patients in whom the disease is of short duration (fig 1). The PP cell mass is not reduced with time; on the contrary, PP-cell hyperplasia may occur in both experimental diabetes ${ }^{17}$ and juvenile diabetics. ${ }^{18} 19$ The PP response to insulin-induced hypoglycaemia depends

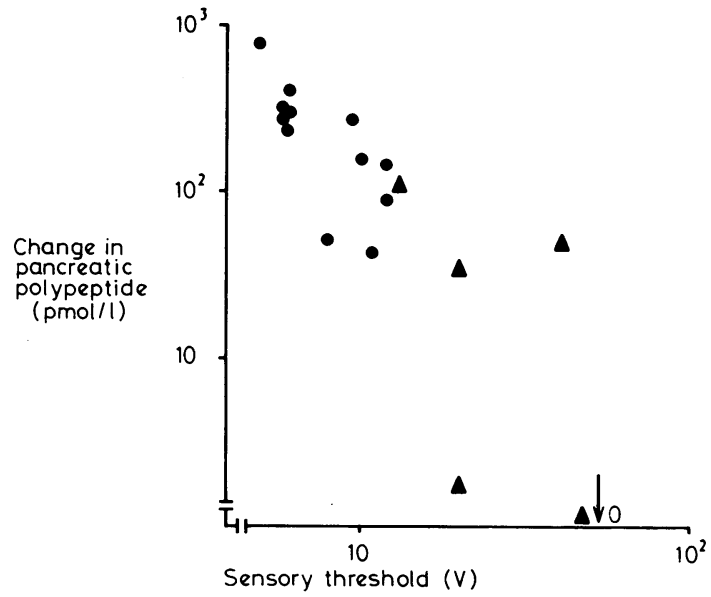

FIG 2-Relation between response of pancreatic polypeptide concentration to hypoglycaemia and threshold of sense of vibration in diabetic patients with $(\boldsymbol{\Delta})$ and without (O) measurable signs of autonomic neuropathy.

completely, however, on an intact nerve supply through the vagus, since no response is found after surgical vagotomy. ${ }^{510}$ Thus we interpret the impaired PP response to insulin-induced hypoglycaemia found in diabetics as being caused by neuropathy of the vagal nerves. If this is correct impaired PP secretion appears to be a highly sensitive indicator of autonomic neuropathy, since the PP response was diminished even in patients with no other measurable signs of autonomic neuropathy but with an increased threshold of the sense of vibration of the peripheral nervous system.

The impaired PP secretion found in the present study is similar to the reported impaired glucagon response to hypoglycaemia in autonomic neuropathy. ${ }^{20} 21$ Although both hormones are stimulated by hypoglycaemia, PP by even smaller decrements in blood glucose concentration than glucagon, ${ }^{15}$ these studies are not completely comparable. In contrast with the glucagon cell the PP cell is not directly influenced by blood glucose concentrations, which is shown by the lack of PP response to hypoglycaemia after vagotomy ${ }^{510}$ and by the nil effect of glucose concentrations on the release of PP from the isolated perfused pancreas. ${ }^{22}{ }^{23}$

We cannot exclude the possibility that the impaired response of PP concentrations to hypoglycaemia that appears with time might be caused by another complication of diabetes unrelated to neuropathy but also appearing with time. In the present study, however, we found a highly significant correlation between deterioration of the PP response to hypoglycaemia and an increasing threshold of the vibration sense.

We thank Evy Dørge and Anette Thorburn for skilled technical help and are grateful to Dr R E Chance, Lilly Research Laboratory, Indiana, USA, for donating highly purified pancreatic polypeptides and antisera. TWS was supported by grants from the Danish Medical Research Council (project No 512-8812 and 512-10545) and the Danish Association of Diabetics (Landsforeningen for Sukkersyge).

Requests for reprints should be addressed to Dr T W Schwartz, Institute of Medical Biochemistry, University of Aarhus, DK-8000 Aarhus C, Denmark.

\section{References}

${ }^{1}$ Hosking, D J, Bennet, T, and Hampton, J R, Diabetes, 1978, 27, 1043.

2 Katz, L A, and Spiro, H M, New England fournal of Medicine, 1966, 275, 1350.

3 Baron, J H, British Medical fournal, 1974, 3, 408.

4 Hosking, D J, et al, British Medical fournal, 1975, 2, 588.

${ }^{5}$ Schwartz, T W, et al, fournal of Clinical Investigation, 1978, 61, 781.

${ }^{6}$ Schwartz, T W, Lancet, 1978, 2, 43.

7 Schwartz, T W, Stenquist, B, and Olbe, L, Gastroenterology, 1979, 76, 14

8 Schwartz, T W, et al, Lancet, 1976, 1, 1102. 
${ }^{9}$ Taylor, I L, et al, American fournal of Physiology, 1978, 235, E443.

${ }^{10}$ Adrian, T E, et al, Lancet, 1977, 1, 161.

11 Schwartz, T W, et al, Gut, 1978, 19, 982.

12 Hilsted, J, and Jensen, S B, Acta Medica Scandinavica, 1979, 215, 385.

13 Jersild, M, and Lauritzen, E, Diabète, 1957, 6, 237.

14 Trinder, P, Fournal of Clinical Pathology, 1969, 22, 246

15 Floyd, J C, et al, Recent Progress in Hormone Research, 1977, 33, 519.

16 Levitt, N S, et al, Scandinavian fournal of Gastroenterology, 1978, 13, suppl No 49 , p 115.

17 Sundler, F, et al, Cell and Tissue Research, 1977, 178, 307.
18 Gepts, W, and De Mey, J, Diabetes, 1978, 27, suppl No 1, p 251.

19 Gepts, W, De Mey, J, and Marichal-Pipeleers, M, Diabetologia, 1977, 13, 27.

${ }^{20}$ Maher, T D, et al, Diabetes, 1977, 26, 196.

${ }^{21}$ Campbell, L V, Kraegen, E W, and Lazarus, L, British Medical fournal, $1977,2,1527$.

${ }^{22}$ Adrian, T E, et al, Diabetologia, 1978, 14, 413.

${ }^{23}$ Hermansen, K, and Schwartz, T W, Endocrinology. In press.

(Accepted 2 October 1979)

\title{
Iron-deficiency anaemia and its effect on worker productivity and activity patterns
}

\author{
V R EDGERTON， G W GARDNER，Y OHIRA， K A GUNAWARDENA， B SENEWIRATNE
}

'British Medical fournal, 1979, 2, 1546-1549

\section{Summary and conclusions}

The effects of iron-deficiency anaemia on worker productivity were studied in a tea plantation in Sri Lanka. The quantity of tea picked per day was studied before and after iron supplementation or placebo treatment. After one month's treatment significantly more tea was picked when the haemoglobin $(\mathbf{H b})$ concentration was increased by iron supplementation than when it was not. The degree of improvement was greater in more-anaemic subjects (those with concentrations of 6.0-9.0 $\mathrm{g} \mathrm{Hb} / \mathrm{dl}$ ). The level of physical activity of anaemic subjects in their everyday environment was also recorded for four or 24 hours continuously both before and after treatment. After three weeks these levels were significantly greater in the iron-treated than matched placebo-treated subjects.

The economic implications of increased work productivity with iron treatment are evident, particularly in developing countries. These results also provide strong evidence for the clinical impression that people with iron-deficiency anaemia suffer from tiredness and weakness.

\section{Introduction}

Three fundamentally different questions are relevant to the potential biological effects of iron-deficiency anaemia. Firstly, for example, to an athlete the important question is related to maximal performance capacity. Secondly, to the worker whose survival depends on his job performance the daily work productivity is often a crucial factor, particularly in developing

\footnotetext{
Department of Kinesiology, University of California, Los Angeles, California, USA

V R EDGERTON, PHD, professor

$G$ W GARDNER, PHD, professor

Y OHIRA, MS, research assistant

Department of Medicine, University of Sri Lanka, Peradeniya, Sri Lanka

K A GUNAWARDENA, MD, professor

B SENEWIRATNE, MD, professor
}

countries. A third question is related to a person's general sense of wellbeing or vitality, though it remains to be determined whether this is affected by iron-deficiency anaemia. Since the first question has been dealt with fairly completely, we describe here a study conducted to answer the second and third questions. All experimental procedures were carried out according to guidelines on patient care adopted by Kandy General Hospital.

\section{Methods}

The experimental protocol of this study was described fully to each subject and voluntary consent obtained in all cases. The subjects were allowed to withdraw from the study at any time without forfeiting any benefits of the medical screening programme. From an initial screening of haemoglobin $(\mathrm{Hb})$ concentration in 217 female workers, all of whom lived and worked on the same tea estate (Oodawella) in the Kandy area of Sri Lanka, we established two experimental groups. The $\mathrm{Hb}$ concentration was determined by the cyanmethaemoglobin method. Ages of the subjects ranged from 20 to 60 (mean 35.3) years. Because the labour force was divided into four separate divisions based on geographical location on the estate we matched the subjects within divisions according to their initial $\mathrm{Hb}$ concentration and productivity. Productivity was calculated from the average weight of tea picked per day over the previous 12 months. This pairing on the basis of productivity was considered to be necessary to account for differences in skill between subjects and the regional and seasonal differences in tea growth (yield) between divisions. The study was conducted during the drought season. Therefore, overall productivity was steadily declining in all divisions. In the studies of both productivity and voluntary activity two groups were classified as either a control, or placebo, group or a treatment group. The placebo group received a daily tablet of calcium lactate $(300 \mathrm{mg}$ ), while the treatment group received a tablet of ferrous sulphate $(200 \mathrm{mg})$. Tablets were dispensed daily at either the morning or evening "weigh-in," when the weight of the tea the subjects had picked in half a day was measured and recorded. One of us supervised the procedure daily to make sure all subjects received and swallowed the correct tablet. We were not in contact with the subjects apart from giving them the pills.

In the study of productivity we treated 199 subjects for one month with iron or a placebo. Haemoglobin concentrations and tea productivity were screened again one month after treatment began. The placebo group was then given the same iron medication as the treatment group and the study was continued for one more month At the end of the second month $\mathrm{Hb}$ concentrations were again measured in all subjects and production data calculated.

To determine the effects of iron treatment on voluntary activity we studied nine pairs of subjects. The $\mathrm{Hb}$ concentration was monitored before and eight and 19 diys after treatment with iron or placebo was begun. At the end of about three weeks iron treatment for the placebo group was started.

Physical activity was recorded by placing a device about the size of 